\title{
Effects of a Low, Oral Dose of Nisoldipine on the Systemic and Coronary Hemodynamics and the Prostaglandin Metabolism of Ischemic Heart Disease Patients
}

\author{
Akira Kurita, M.D., Bompei Takase, M.D., Akimi Uehata, M.D., \\ Hiroko Sugawara, M.D., Toshihiko Nishioka, M.D., \\ Toshiharu Maruyama, M.D., Kimio Satomura, M.D., \\ Shuji Kondo, M.D., Kyoichi Mizuno, M.D., \\ Kazushige Isojrma, M.D., Haruo Nakamura, M.D., \\ Toshikazu Kanda, Ph.D.,* and Yoshio Yoshino, M.D.*
}

\section{Summary}

This study investigated the effects of a low dose of nisoldipine $(5 \mathrm{mg}$, p.o.) in 10 patients with ischemic heart disease. The patients were subjected to a $90-\mathrm{min}$ exercise regimen before and after a $5 \mathrm{mg}$ dose of nisoldipine, using a supine bicycle ergometer adjusted to each patient's limitations. The mean blood plasma level of nisoldipine was $3.8 \pm 3.1$ (SD) $\mathrm{ng} / \mathrm{ml}$. The drug significantly decreased the systolic arterial pressure in patients throughout the experimental session, whereas a change in the diastolic arterial pressure appeared only at the submaximal stage of the exercise. Additionally, at maximal exercise, nisoldipine caused a decrease in the mean coronary sinus pressure from $11.4 \pm 7 \mathrm{mmHg}$ to $6.5 \pm 5$ $\mathrm{mmHg}(\mathrm{p}<0.01)$. By contrast, while at rest, nisoldipine decreased the coronary vascular resistance from $1.5 \pm 0.7 \mathrm{mmHg} / \mathrm{ml} / \mathrm{min}$ to $1.0 \pm 0.7$ $\mathrm{mmHg} / \mathrm{ml} / \mathrm{min}(\mathrm{p}<0.05)$. After exercise, the drug decreased thromboxane $B_{2}$ levels from $1133 \pm 907 \mathrm{pg} / \mathrm{ml}$ to $720 \pm 379 \mathrm{pg} / \mathrm{ml}(\mathrm{p}<0.05)$ in the coronary sinus blood, and increased the 6 keto-prostaglandin $F_{1 \alpha}$ levels from $465 \pm 135 \mathrm{pg} / \mathrm{ml}$ to $559 \pm 167 \mathrm{pg} / \mathrm{ml}(\mathrm{p}<0.05)$ in brachial artery blood. This suggests that a low, oral dose of nisoldipine can moderately improve the systemic and coronary hemodynamics and afterloads, and may assist in improving the prostaglandin metabolism in ischemic heart disease patients.

From the Department of Internal Medicine, National Defense Medical College, Tokorozawa, Saitama, Japan.

* Department of Biochemistry, Nippon Medical School, Tokyo.

Address for reprints: Akira Kurita, M.D., Department of Internal Medicine, National Defense Medical College, 3-2 Namiki, Tokorozawa, Saitama 359, Japan.

The paper was partly presented at the 37 th Annual Meeting of the American College of Cardiology at Atlanta, Georgia in 1988.

Received for publication April 13, 1989.

Accepted November 8, 1989. 


\section{Additional Indexing Words:}

Nisoldipine Prostaglandin metabolism Ischemic heart disease

CEVERAL recent studies have shown that slow channel blocking drugs, $D$ which are effective in the management of obstructive and vasospastic coronary artery disease, are also efficacious in inhibiting platelet aggregation. ${ }^{1)-5}$ Typical slow channel blocking drugs, such as nifedipine and verapamil, inhibit the secondary ( $\mathrm{TXA}_{2}$-dependent) wave of ADP-induced platelet aggregation and appear to have beneficial effects on prostagladin metabolism in the event of myocardial ischemia. ${ }^{6)}$

Nisoldipine, a new calcium channel blocker, is a dihydropyridine derivative that is structurally similar to nifedipine (Fig. 1). It has stronger systemic and coronary hemodynamic effects ${ }^{7 /-9}$ than other dihydropyridines, but it may also have a potent effect on prostaglandin metabolites. Although an intravenous infusion of nisoldipine has been shown to increase the myocardial supply in excess of demand, ${ }^{10-12)}$ only a few studies have examined its effects on prostaglandin metabolism after either intravenous or oral administration. This study investigated the effects of a low, oral dose of nisoldipine on systemic and coronary hemodynamics, and on prostaglandin metabolism in patients

Table I. Summary of the Effects of Nisoldipine ( $5 \mathrm{mg}$ oral dose) with Chronic, Stable Angina Pectoris

\begin{tabular}{|c|c|c|c|c|}
\hline & Pts & Rest & Rest (N) & Sub-E \\
\hline HR & 10 & $63 \pm 11$ & $70 \pm 14$ & $84 \pm 8$ \\
\hline $\mathrm{BPs}_{\mathrm{s}}$ & 10 & $165 \pm 23$ & $151 \pm 20^{* *}$ & $187 \pm 25$ \\
\hline $\mathrm{BPd}$ & 10 & $86 \pm 15$ & $82 \pm 15$ & $96 \pm 18$ \\
\hline PRP & 10 & $104 \pm 26$ & $101 \pm 27$ & $158 \pm 30$ \\
\hline $\mathrm{ST}$ & 10 & & & \\
\hline CSPm & 10 & $7.4 \pm 4$ & $4.9 \pm 5^{*}$ & $10 \pm 5$ \\
\hline CSF & 10 & $84 \pm 32$ & $109 \pm 45$ & $129 \pm 48$ \\
\hline CVR & 10 & $1.5 \pm 0.7$ & $1.0 \pm 0.7^{*}$ & $1.1 \pm 0.3$ \\
\hline $\mathrm{MVO}_{2}$ & 8 & $9.5 \pm 4$ & $10.3 \pm 4$ & \\
\hline $\mathrm{TXB}_{2}(\mathrm{~A})$ & 10 & $516 \pm 235$ & $516 \pm 159$ & \\
\hline $\mathrm{TXB}_{2}(\mathrm{CS})$ & 10 & $770 \pm 417$ & $477 \pm 200^{*}$ & \\
\hline $6 \mathrm{KPGF}_{1 a}(\mathrm{~A})$ & 10 & $414 \pm 128$ & $463 \pm 141$ & \\
\hline $6 \mathrm{KPGF}_{1 \alpha}(\mathrm{CS})$ & 10 & $442 \pm 181$ & $396 \pm 106$ & \\
\hline $\mathrm{TXB}_{2} / 6 \mathrm{KPGF}_{1 \alpha}(\mathrm{A})$ & 10 & $1.3 \pm 0.6$ & $1.2 \pm 0.4$ & \\
\hline $\mathrm{TXB}_{2} / 6 \mathrm{KPGF}_{1 \alpha}(\mathrm{CS})$ & 10 & $2.2 \pm 0.4$ & $1.2 \pm 0.4$ & \\
\hline
\end{tabular}

Each value represents the mean $\pm \mathrm{SD}$. $\mathrm{N}=$ post nisoldipine; Sub-E=submaximum of exercise; Max $-\mathrm{E}=$ maximum of exercise; Post $5^{\prime}=$ post $5 \mathrm{~min}$ of exercise; HR=heart rate (bpm); $B P_{s}=$ systolic blood pressure ( $\mathrm{mmHg}$ ); $\mathrm{BPd}=$ diastolic blood pressure ( $\mathrm{mmHg}$ ); $\mathbf{P R P}=$ pressure rate product $\left(\mathrm{mmHg} / \mathrm{bpm} \cdot 10^{2}\right) ; \mathrm{CSPm}=$ mean coronary sinus pressure $(\mathrm{mmHg}) ; \mathrm{CSF}=$ coronary sinus 
<smiles>CCCC(=O)C1=C(C)NC(C)=C(C(=O)OCC)C1c1ccccc1[N+](=O)[O-]</smiles>

NISOLDIPINE<smiles>COC(=O)C1=C(C)NC(C)=C(C(C)=O)C1c1ccccc1[N+](=O)[O-]</smiles>

\section{NIFEDIPINE}

Fig. 1. Chemical structures of the dihydropyridine derivatives, nifedipine and nisoldipine.

with chronic, stable angina pectoris. The rationale for this study was that low, oral doses of the medication would be both economically and physiologically beneficial. Further, a deeper knowledge of the effects of nisoldipine on the prostaglandin metabolites is desired, for they are known to play an important role in the pathogenesis of ischemic heart disease (IHD). ${ }^{13)-15}$ )

on the Hemodynamics and the Prostaglandin Metabolism of Patients at Rest, During and After Exercise

\begin{tabular}{|c|c|c|c|c}
\hline Sub-E (N) & Max-E & Max-E (N) & Post 5' & Post 5' (N) \\
\hline $87 \pm 10$ & $110 \pm 16$ & $112 \pm 19$ & $72 \pm 16$ & $81 \pm 21^{*}$ \\
$172 \pm 21^{* *}$ & $216 \pm 25$ & $202 \pm 18^{* *}$ & $162 \pm 21$ & $152 \pm 25^{*}$ \\
$89 \pm 17^{* *}$ & $98 \pm 18$ & $93 \pm 16$ & $82 \pm 10$ & $78 \pm 12$ \\
$151 \pm 27$ & $233 \pm 48$ & $224 \pm 52^{*}$ & $118 \pm 33$ & $124 \pm 46$ \\
& $4.3 \pm 4$ & $2.7 \pm 1.6^{*}$ & & \\
$6.1 \pm 5^{*}$ & $11.4 \pm 7$ & $6.5 \pm 5^{* *}$ & $7 \pm 5$ & $5.4 \pm 4$ \\
$148 \pm 40$ & $210 \pm 112$ & $226 \pm 94$ & & \\
$0.9 \pm 0.3$ & $0.8 \pm 0.3$ & $0.6 \pm 0.3^{*}$ & & \\
& $20 \pm 8$ & $20 \pm 9$ & & \\
& $585 \pm 185$ & $585 \pm 171$ & & \\
& $1133 \pm 907$ & $720 \pm 379^{*}$ & & \\
& $465 \pm 135$ & $559 \pm 167^{*}$ & & \\
& $447 \pm 146$ & $469 \pm 134$ & & \\
& $1.3 \pm 0.5$ & $1.1 \pm 0.5^{*}$ & & \\
& $2.5 \pm 1.6$ & $2.5 \pm 0.2$ & & \\
& & &
\end{tabular}

flow $(\mathrm{ml} / \mathrm{min}) ; \mathrm{CVR}=$ coronary vascular resistance $(\mathrm{mmHg} / \mathrm{ml} / \mathrm{min}) ; \mathrm{MVO}_{2}=$ myocardial oxygen content $\left(\mathrm{mlO}_{2} / \mathrm{min}\right) ; \mathrm{TXB}_{2}=$ thromboxane $\mathrm{B}_{2}(\mathrm{pg} / \mathrm{ml}) ; 6 \mathrm{KPGF}_{1 \alpha}=6$ keto-prostaglandin $\mathrm{F}_{1 \alpha}(\mathrm{pg} / \mathrm{ml})$; $A=$ arterial blood; $\mathrm{CS}=$ coronary sinus blood. $*<0.05, * *<0.01$ vs premedication. 


\section{Methods}

\section{Selection of patients:}

Patients with a predominant history of angina while at rest or an ST segment elevation during episodes of chest pain were excluded from this study. Similarly, patients with severe hypertension, a valvular heart disease, signs of congestive heart failure, intraventricular conduction disturbances, or any other condition likely to influence the ST segment "at rest" were also excluded.

Ten patients, ranging in age from 44 to 65 (mean age: 50), with stable angina pectoris were tested. All had reproducible, exercise-induced angina, associated with horizontal or downsloping ST segment depression of $0.1 \mathrm{mV}$ or more for at least $80 \mathrm{msec}$ after the $\mathrm{J}$ point of the baseline of a treadmill test. Each had had at least one fixed coronary artery stenosis (a 70\% or greater narrowing of the luminal diameter), determined by routine coronary arteriography. The left ventricular contraction was normal in 8 patients, while the remaining 2 showed hypokinesis.

Beta blockers, calcium blocking drugs, or any other agents that might affect the exercise data were discontinued 14 days prior to the start of the exercise regimen. Platelet-inhibitory drugs, such as aspirin, sulfapyrazone or other agents affecting the prostaglandin release, were also discontinued 7 days prior to testing. Finally, patients did not receive any nitrates except sublingual nitroglycerin within 6 hours of testing.

\section{The test procedure:}

All selected patients underwent a graded, supine bicycle exercise test devised by Minjhart. The exercise was started at 50 watts, with the work load being increased 25 watts every $3 \mathrm{~min}$ up to each patient's optimal work load. The exercise was terminated on complaint of a chest pain or on observation of a $0.1 \mathrm{mV} \mathrm{ST} \mathrm{segment} \mathrm{depression,} \mathrm{with} \mathrm{horizontal} \mathrm{or} \mathrm{downsloping}$ patterns, for $80 \mathrm{msec}$ from the $\mathrm{J}$ point. Individual exercise thresholds had been determined at least $90 \mathrm{~min}$ prior to the start of exercise and patients underwent their predetermined work loads.

Measurements were taken in the following manner. Under local anesthesia, a sheath was inserted into an antecubital vein, through which a $7 \mathrm{Fr}$ thermodilution catheter (Wilton Lab.) was inserted and positioned in the mid-coronary sinus (CS). The positioning of the catheter was then carefully checked by fluoroscopy. The coronary sinus blood flow (GSF) was measured and calculated by the method described by Ganz ct al. ${ }^{16)}$ A 4 Fr wedge catheter was introduced into the antecubital vein of the opposite arm and 
positioned in the mid-CS to measure the CS pressure. The brachial arterial pressure was obtained through a 21 -gauge, $5.5 \mathrm{~cm}$ teflon needle inserted into the brachial artery. All hemodynamic data were recorded with an 8-channel recorder (Hewlett-Packard 1840). An Acudynamic apparatus was used $^{17)}$ to obtain the brachial artery and the CS pressures precisely. A threelead electrocardiogram was taken continuously during the regimen, using a Marquette Case I system, and the $\mathrm{ST}$ integral in both $\mathrm{aV}_{\mathrm{F}}$ and $\mathrm{V}_{5}$ was obtained by a $9801 \mathrm{~F}$ and PIAS-1 analyzing system (NEC, Tokyo) and was expressed in $\mu \mathrm{v}$-sec. ${ }^{18}$

Measurements at rest were taken after all hemodynamic parameters had stabilized for at least $5 \mathrm{~min}$. As soon as the hemodynamics and CSF were recorded and the blood samples were collected, exercise testing of each patient was performed until the predetermined threshold was reached. When the initial testing was concluded, patients were given $5 \mathrm{mg}$ of nisoldipine orally. Ninety minutes later, after the hemodynamics and CSF were recorded and blood samples collected, the second exercise phase with the same work load was then started. Under this exercise regimen, the effects of nisoldipine on the hemodynamics while at rcst, at the middle, and at peak of exercise, as well as at $5 \mathrm{~min}$ after the end of exercise were later compared. Similarly, the effects of nisoldipine on the CSF were measured at rest and immediately after exercise.

\section{Calculations and blood sample collection:}

The brachial arterial systolic and diastolic pressures were measured every $3 \mathrm{~min}$ and a mean value for 10 beats was recorded. The pressure rate product was obtained by calculating heart rate multiplied by the systolic pressure and expressed as $\mathrm{mmHg} / \mathrm{bpm} \cdot 10^{2}$. The CVR was calculated as the CSF divided by the mean arterial pressure and expressed in $\mathrm{mmHg} / \mathrm{ml} / \mathrm{min}$.

Blood specimens were collected before and immediately after the exercise testing. The first $\mathrm{ml}$ of blood was discarded and approximately $10 \mathrm{ml}$ of both the arterial and CS blood were used. The blood samples were mixed and immediately chilled for $30 \mathrm{~min}$ before centrifugation at 2,000 $\mathrm{g}$ for $20 \mathrm{~min}$ at $4{ }^{\circ} \mathrm{C}$. The level of $\mathrm{TXB}_{2}$ was measured by a radioimmunoassay (RIA) of $7 \mathrm{ml}$ blood in $0.5 \mathrm{ml}$ of $4.5 \mathrm{mM}$ EDTA and $1 \mathrm{mM}$ of an acetylsalicylic acid solution to prevent an ' in vitro' breakdown of the arachidonic acid and prostagladin release. The ${ }^{3} \mathrm{H}$-standard $\mathrm{TXB}_{2}$ and its antibody were obtained from a commercial source (New England Nuclear, Boston, Ma). The $6 \mathrm{KPGF}_{1 \alpha}$ was measured as a stable product of prostacyclin by RIA, using a standard antibody to $6 \mathrm{KPGF}_{1 \alpha}$ (New England Nuclear). Measurements of $\mathrm{TXB}_{2}$ and $6 \mathrm{KPGF}_{1 \alpha}$ were performed according to a method described by 
Kawahara et $\mathrm{al}^{19)}$ and the normal values were $320 \pm 13 \mathrm{pg} / \mathrm{ml}$ and $414 \pm$ $49 \mathrm{pg} / \mathrm{ml}$, respectively. The reproducibility of the assay for a duplicate determination by the double blind method was $94.4 \%$ and the coefficient of the variation of the same sample was between 8 to $17 \%$. Our normal values for $\mathrm{TXB}_{2}$ and $6 \mathrm{KPGF}_{1 \alpha}$ were comparable to RIA results previously reportcd in the literature. ${ }^{20)-22}$ )

The oxygen content and capacity were determined by manometric analysis and the global myocardial oxygen consumption was derived in the following manner: the arterial $\mathrm{O}_{2}$ content minus the $\mathrm{CS} \mathrm{O}_{2}$ content times the CSF times $10^{2}$. The plasma nisoldipine levels were obtained by liquid chromatography and all results are presented in means \pm SD. The statistical analysis of the at rest and exercise variables were calculated using the Student's t-test.

\section{Results}

No adverse side effects appeared after the oral intake of $5 \mathrm{mg}$ of nisoldipine. The mean serum nisoldipine level was $3.8 \pm 3.1 \mathrm{ng} / \mathrm{ml}$ after approximately $90 \mathrm{~min}$.

Effects of nisoldipine while at rest:

Nisoldipine produced an increment in the heart rate and a significant fall in the systolic arterial pressure (prior medication, $165 \pm 23$; post, $151 \pm$ $20 \mathrm{mmHg} ; \mathrm{p}<0.01$ ), though the diastolic arterial pressure and pressure rate product did not change significantly. The mean CSP decreased significantly

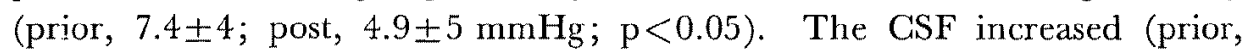
$84 \pm 32$; post, $109 \pm 45 \mathrm{ml} / \mathrm{min} ; \mathrm{p}<0.05)$ and the coronary vascular resistance (CVR) dropped significantly (prior, $1.5 \pm 0.7$; post, $1.0 \pm 0.7 \mathrm{mmHg} / \mathrm{ml} / \mathrm{min}$; $\mathrm{p}<0.05)$.

The myocardial oxygen consumption presented similar values prior and post medication. The $\mathrm{TXB}_{2}$ in the brachial artery remained unchanged, whereas the $\mathrm{TXB}_{2}$ in the CS blood decreased significantly. However, the $6 \mathrm{KPGF}_{1 \alpha}$ in the brachial artery and the $\mathrm{TXB}_{2} / 6 \mathrm{KPGF}_{1 \alpha}$ ratio were not significantly affected by nisoldipine.

\section{Effects of nisoldipine during exercise:}

The hemodynamic and metabolic effects of the medication were compared at the time of exercise. The ingestion of nisoldipine did not provoke angina attacks. Further, the ST segment integral was significantly reduced (prior medication, $4.3 \pm 4$; post, $2.7 \pm 1.6 \mu \mathrm{v}-\mathrm{sec} ; \mathrm{p}<0.05$ ). The heart 
rate did not change appreciably either at the submaximum or at the maximum of exercise. The heart rate, however, was significantly elevated 5 min after exercise. Although the systolic arterial pressure decreased significantly throughout the testing, the diastolic arterial pressure was unaffected.

The pressure rate product decreased at the maximum of exercise (prior, $233 \pm 48$; post, $\left.224 \pm 52 \mathrm{mmHg} / \mathrm{bpm} \cdot 10^{2} ; \mathrm{p}<0.05\right)$ and the mean CS pressure decreased significantly at both the submaximum and the maximum exercise levels. The CSF was unaffected, but the CVR was reduced (prior, $0.8 \pm 0.3$; post, $0.6 \pm 0.3 \mathrm{mmHg} / \mathrm{ml} / \mathrm{min} ; \mathrm{p}<0.05$ ). Further, the $\mathrm{TXB}_{2}$ level decreased significantly in the CS blood (prior, $1133 \pm 907$; post, $720 \pm 379 \mathrm{pg}$ / $\mathrm{ml} ; \mathrm{p}<0.05)$. Finally, the $6 \mathrm{KPGF}_{1 \alpha}$ level in brachial artery blood increascd (prior, 465 \pm 135 ; post, $559 \pm 167 \mathrm{pg} / \mathrm{ml} ; \mathrm{p}<0.05$ ), whereas the $\mathrm{TXB}_{2} / 6 \mathrm{KPGF}_{1 \alpha}$ in the $\mathrm{CS}$ was not reduced significantly.

\section{Discussion}

Systemic and coronary hemodynamics:

Ninety minutes after ingestion of $5 \mathrm{mg}$ of nisoldipine, the concentration in plasma was found to be $3.8 \pm 3.1 \mathrm{ng} / \mathrm{ml}$. This is a rather low level, compared to the effect of higher ingested doses (10 or $20 \mathrm{mg}$ ). A study regarding the effect of the drug in Japanese patients has shown that, $1 \mathrm{hr}$ after an oral $10 \mathrm{mg}$ or $20 \mathrm{mg}$ dose, the plasma concentration peak values are $6.0 \pm$ $3.6 \mathrm{ng} / \mathrm{ml}$ and $14 \pm 3.8 \mathrm{ng} / \mathrm{ml}$, respectively. ${ }^{23)}$ There are no other reports regarding plasma concentration levels from $5 \mathrm{mg}$ doses. Even at this low blood concentration, however, nisoldipine was shown to have some effect. The systolic arterial pressure and the CVR were reduced and the CSF increased significantly, but the increment in the heart rate was not remarkable.

During exercise, given the same work load, the systolic arterial pressure and the ST segment were reduced significantly by low-dose nisoldipine therapy. The mean CS pressure also was reduced without apparently affecting the diastolic pressure. Since the coronary perfusion pressure is regulated by the diastolic artery and the coronary sinus-pressure, ${ }^{24)}$ our data suggest that nisoldipine can increase perfusion of the myocardium. Moreover, the increment in the pressure rate product, an indirect result of the myocardial oxygen demand, was reduced during the second exercise regimen. Thus, after the oral dose of nisoldipine, the exercise was performed with less of a myocardial oxygen demand.

Similar results were observed by Lam et al, ${ }^{25)}$ who compared the effects of nisoldipine in exercise testing by utilizing the drug and a placebo in a double-blind test. Cream et al ${ }^{26}$ ) also have reported that a $5 \mathrm{mg}$ oral dose 
of nisoldipine did not change the heart rate or the systolic arterial pressure appreciably. Further, they found that the exercise time could be prolonged with no change in the summed ST segment depressions, and that a stepwise improvement occurred in extending the exercise parameters with increments in the dosage from 5 to $20 \mathrm{mg}$. Our observation of an improvement with only a $5 \mathrm{mg}$ dose may be explained by the physique of the average Japanese, who has a thinner skin and is smaller than the average Caucasian. ${ }^{27}$ Thus, our dosage was sufficient to improve the exercise hemodynamic parameters.

Hemodynamic data indicated that nisoldipine increased the CSF by $29 \%$ and reduced the CVR by $33 \%$ while at rest. After medication, the CVR was also reduced by $25 \%$ during excreise. There have been no previous reports about the effects from $5 \mathrm{mg}$ oral doses of nisoldipine on coronary hemodynamics. An increment in the CSF by an intravenous administration of nisoldipine, though, has been confirmed by Soward et $\mathrm{al}^{10)}$ and Serruys et al, ${ }^{11)}$ who reported an increase of 21 to $31 \%$; they also observed a significant reduction in the GVR. Similarly, our results suggest that an oral dose improves coronary hemodynamics.

When measuring the CSF by the thermodilution technique, the positioning of the catheter is crucial. According to Magorien et al, ${ }^{28}$ the correlation of consecutive values of the CSF, obtained from measurements by this technique, revealed coefficients of 0.94 at rest, and 0.93 during exercise. For our measurements, we carefully monitored the position of the catheter tip by fluoroscopy. This procedure ensured that the proper catheter position was maintained, so that the CSF values we obtained were reliable throughout exercise testing.

\section{Prostaglandin metabolism:}

The effects of nisoldipine on prostagladin metabolism were also investigated because recent studies indicate that it plays an important role in the pathogenesis of myocardial ischemia. ${ }^{13)-15)}$ Dusting et al $^{13)}$ have proposed a new, homeostatic mechanism in the maintenance of a normal CSF, dependent on the balance among the proaggregative vasoconstrictor, the $\mathrm{TXA}_{2}$ formed by activate platelets, and the antiaggregative vasodilator prostacyclin, which is produced by the vascular endothelium. To test this hypothesis, we studied the effects of nisoldipine on the $\mathrm{TXB}_{2}$ and $6 \mathrm{KPGF}_{1 \alpha}$ levels in both the arterial and CS blood before and immediately after the exercise regimen. Since nisoldipine is structurally similar to nifedipine and has been reported to have a stronger vasodilative effect, ${ }^{7-9)}$ these studies tested for an effect nisoldipine in the formation of $\mathrm{TXB}_{2}$ or in the production of $6 \mathrm{KPGF}_{1 \alpha}$. 
Our results have revealed that nisoldipine reduced the $\mathrm{TXB}_{2}$ in the blood of the coronary sinus more markedly than in the blood of the artery. The $\mathrm{TXB}_{2}$ level in the coronary sinus blood was reduced by $38 \%$ at rest, and by $36 \%$ during exercise, whereas there was no apparent change in the arterial blood. Since the blood of the coronary sinus received about $94 \%$ of the coronary artery inflow, ${ }^{29)}$ our results suggest that the myocardium may be perfused with blood that has a lower affinity for aggregation, which would provide a beneficial effect to the ischemic myocardium.

Nisoldipine also increased the $6 \mathrm{KPGF}_{1 \alpha}$ in the arterial blood by $11 \%$ at rest and by $20 \%$ during exercise. Accordingly, nisoldipine reduced the $\mathrm{TXB}_{2} / 6 \mathrm{KPGF}_{1 \alpha}$ in the arterial blood by $11 \%$ and also reduced the ratio in the CS blood by $17 \%$ during exercise. This suggests a slight improvement of prostaglandin metabolism. The mechanisms of action of dihydropyridine derivatives are uncertain. However, these effects on prostaglandin metabolism, both in the artery and coronary sinus blood suggest that nisoldipine exerts either a primary beneficial effect on prostaglandin metabolism, or a secondary effect due to the coronary or systemic hemodynamics.

Previous studies ${ }^{51,6), 30)}$ have demonstrated that diltiazem inhibits ADP, collagen, and the arachidonate acid-induced platelet aggregation and release, and that verapamil and nifedipine are capable of inhibiting epinephrineinduced platelet aggregation and the $\mathrm{TXB}_{2}$ release from platelets challenged with epinephrine. Schrör et al ${ }^{31)}$ have also reported that $10 \mathrm{mg}$ of nisoldipine inhibited platelet aggregation and thromboxane formation in healthy men after high doses of collagen, which may be related to an increased resistance in the platelet membrane against foreign stimuli. Further, Johnson et al $^{32)}$ have reported that dihydropyridines are competitive antagonists of the $\mathrm{TXA}_{2}-\mathrm{PGH}_{2}$ receptor. However, the precise mechanism involved in these effects at the level of either platelet $\mathrm{TXA}_{2}-\mathrm{PGH}_{2}$ receptors or vascular $\mathrm{TXA}_{2}-\mathrm{PGH}_{2}$ rcceptors is uncertain.

In conclusion, nisoldipine may improve prostagladin metabolism by either inhibiting the formation of $\mathrm{TXB}_{2}$, or facilitating the production of prostacyclin in the vessel wall. These effects may be related to a primary or secondary improvement in the systemic or coronary hemodynamics. Although further study is required to determine whether nisoldipine has a beneficial homeostatic effect on the metabolism during myocardial ischemia, our results have demonstrated that even a low, oral dose of nisoldipine moderately affects the systemic and coronary hemodynamics and assists in improving the prostagladin metabolism in IHD patients. 


\section{AGKNOWLEDGMents}

The authors would like to thank Mr. Joseph A. Grace for his help in reading this manuscript.

\section{REFERENCES}

1. Addonizio VP, Fisher CA, Edmunds LH: Effects of verapamil and nifedipine on platelet activation. Girculation 62 (suppl III): 326, 1980

2. Ikeda $\mathrm{Y}$, Kikuchi $\mathrm{M}$, Toyama $\mathrm{K}$, Watanabe $\mathrm{K}$, Ando $\mathrm{Y}$ : Inhibition of human platelet functions by verapamil. Thromb Haemost $\mathbf{4 5}$ (suppl 2): 158, 1981

3. Burns ER, Frishman WH: The antiplatelet effects of calcium channel blockers add to their antianginal properties. Int J Cardiol 4: 372, 1983

4. Chierchia S, Crea F, Bernini W, Gensini G, Parodi O, De Caterina R, Maseri A: Antiplatelet effects of verapamil in man. Am J Cardiol 47: 399, 1981

5. Ono $\mathrm{H}$, Kimura $\mathbf{M}$ : Effects of $\mathrm{Ca}^{2+}$-antagonistic vasodilators, diltiazem, nifedipine, perhexiline and verapamil, on platelet aggregation in vitro. Arzneim Forsch 31: 1131, 1981

6. Johnson GJ, Leis LA, Francis GS: Disparate effects of the calcium-channel blockers, nifedipine and verapamil, on $\alpha_{2}$-adrenergic receptors and thromboxane $\mathrm{A}_{2}$-induced aggregation of human platelets. Circulation 73: 847, 1986

7. Kazda S, Garhoff B, Meyer H: Pharmacology of a new calcium antagonistic compound isobutyl methyl 1,4 dihydro-2, 6-dimethyl-4-(2-nitrophenyl)-3,5-puridinedicarbaoxylate (nisoldipine, Bay k 5552). Arzneim Forsch $30: 2144,1980$

8. Warltier DC, Meila CM, Gross GJ, Brooks HL: Blood flow in normal and ischemic myocardium after verapamil, diltiazem and nisoldipine (Bay $\mathrm{k}$ 5552), a new dihydropyridine calcium antagonist. J Pharmacol Exp Therap 218: 296, 1981

9. Vogt A, Neuholds KL, Krenzer H: Hemodynamic effects of the new vasodilator drug Bay k 5552 in man. Arzneim Forsch 30: 2162, 1980

10. Soward AL, Feyter PJD, Hugenholtz PG, Serruys PW: Maintenance of increased coronary blood flow in excess of demand by nisoldipine administered as an intravenous infusion. Am J Cardiol 58: 1.199, 1986

11. Serruys PW, Suryapranta H, Planellas J, Wijns W, Vanhaleweyk LJ, Soward AL, Jaski BE, Hugenholtz PG: Acute effects of intravenous nisoldipine on left ventricular function and coronary hemodynamics. Am J Cardiol 56: 140, 1985

12. Roussau MF, Vincent MF, Hoof FV, Bergha VD, Charlier AA, Pouleur H: Effects of nicardipine and nisoldipine on myocardial metabolism, coronary blood flow and oxygen supply in angina pectoris. Am J Cardiol 54: 1189, 1984

13. Dusting GJ, Moncada S, Vane JR: Prostaglandins, their intermediates and precursors: Cardiovascular actions and regulatory roles in normal and abnormal circulatory systems. Prog Cardiovasc Dis 21: 405, 1979

14. Hirsh PD, Hillis LD, Campbell WB, Firth BG, Willerson JT: Release of prostaglandins and thromboxane into the coronary circulation in patients with ischemic heart disease. New Engl J Med 304: 685, 1981

15. Vane JR: Prostaglandin and cardiovascular system. Br Heart J 49: 405, 1983

16. Ganz W, Tamura K, Marcus HS, Donoso R, Yoshida S, Swan HJC: Measurement of coronary sinus blood flow by continuous thermodilution in man. Circulation 44: 189, 1971

17. Garner RM: Direct blood flow pressure measurement-dynamic response requirement. Anestheology 54: 227, 1981

18. Shefield LT, Holt JT, Laster FM, Conroy DV, Reeves AJ: On-line analysis of the exercise electrocardiogram. Circulation 40: 935, 1969

19. Kawahara K, Sugita H, Masanori O, Takata N: A simple, rapid and simultaneous extrac- 
tion of thromboxane $B_{2} 6$ keto-prostaglandin $F_{1 a}$ and prostaglandin $E_{2}$. Jpn J Inflammation 7: 511,1987

20. Metha J, Metha P, Feldman RL, Horalek G: Thromboxane release in coronary artery disease: spontaneous versus pacing-induced angina. Am Heart J 107: 286, 1984

21. Tada M, Kuzuya T, Inoue M, Kodama K, Mishima M, Yamada M, Inui M, Abe H: Elevation of thromboxane $B_{2}$ levels in patients with classic and variant angina pectoris. Circulation 64: 1107, 1981

22. Morris HG, Sherman NA, Shepperdson FT: Variable associated with radioimmunoassay of prostaglandins in plasma. Prostaglandins 21: 771, 1981

23. Iimura H, Kato K: Bay k 5552 Phase I study. Clinical Report 22: 29, 1988

24. Marcus ML: The Coronary Circulation in Health and Disease, McGraw-Hill, New York, p 93, 1983

25. Lam J, Chaitman BR, Crean PA, Blum R, Waters DD: A dose-ranging, placebo-controlled, double-blind trial of nisoldipine in effort angina. Duration and extent of antianginal effects. J Am Coll Cardiol 6: 447, 1986

26. Grean PA, Waters DD, Lam J, Chaitman BR: Comparative antianginal effects of nisoldipine and nifedipine in patients with chronic stable angina. Am Heart J 113: 261, 1987

27. Key A: Goronary heart disease in seven countries. Relative body weight. Girculation 41 (suppl I): I-199, 1968

28. Magorien RD, Friederick J, Lefer CV, Chaitman BR: Influence of exercise on coronary sinus blood flow determinations. Am J Cardiol 50: 659, 1987

29. Hood WB : Regional venous drainage of the human heart. Br Heart J 30: 105, 1968

30. Shino A, Sasaki $Y$, Inamaso $M$ : In vitro effects of the coronary vasodilator diltiazem on human and rat platelets. Throb Res $13: 941,1978$

31. Schrör K, Latta G, Darius H, Klaus W, Ziegler R: Hemmung der plattchenaggregation und thromboxanbildung durch calcium-antagonisten nisoldipine nach einer oralen einmal dosis von $10 \mathrm{mg}$. Klin Wochenschr 63: 16, 1985

32. Johnson GJ, Dunlop PG, Leis LA: From dihydropyridine agonist Bay k 8664 inhibits platelet activation by competitive antagonism of thromboxane $A_{i}$-prostaglandin $\mathrm{H}_{2}$ receptor. Circ Res 62: 494,1988 